\title{
"Influencia da Época de Semeadura sôbre o Rendimento do Nabo" (*)
}

\author{
Salim Simão
}

E. S. A. «Luiz de Queiroz»

(*) Recebido para publicação em 31/10/1960. 


\section{INTRODUÇÃO}

O Nabo, Brassica Napus, L, pertence a família das Cruciferae e se constitui em uma hortaliça de largo consumo em nosso meio.

Com o intuito de se correlacionar o rendimento do Nabo com a época da semeadura iniciamos o presente trabalho.

\section{MATERIAL E MÉTODO}

As investigações sôbre o comportamento do Nabo toram feitas na Horta da Secção de Horticultura da Escola Superior de Agıicultura "Luiz de Queiroz".

Os estudos se prolongaram por 2 anos: 1.952 e 1.953 .

As semeaduras foram feitas diretamente no local definido, espaçada de $0,30 \times 0,10$ metros. Os canteiros possuiam 2,00 x 20,00 metros e recebiam 200 quilos de estercos e 4 quilos de adubo mineral na proporção de $6-10-6$.

O ciclo vegetativo foi de 60 dias. Em cada época de semeadura fizeram-se 4 repetições e colheram-se e pesaram-se de cada uma das parcelas 100 plantas: A variedade utilizada foi "Nabo Chato Branco".

\section{RESULTADOS E DISCUSSÃO}

Apresentamos a seguir nos Quadros I e II os pesos das raizes e das fôlhas de 100 Nabos, registrados em 1952 e 1953.

Os quadros III e IV apresentam os resultados das análises de variância correspondentes ao pêso das raizes e fôlhas em 1952 e nos quadrós V e VI as análises referentes ao ano de 1953. 
QUADRO I

Pêso das raizes e fôlhas de Nabo em 1952 (1)

\begin{tabular}{|c|c|c|c|c|c|c|c|c|c|c|c|c|c|c|c|c|}
\hline \multirow{2}{*}{$\begin{array}{c}\text { Data } \\
\text { Repet. }\end{array}$} & \multicolumn{2}{|c|}{$11-2$} & \multicolumn{2}{|c|}{$11-3$} & \multicolumn{2}{|c|}{$10-4$} & \multicolumn{2}{|c|}{$9-5$} & \multicolumn{2}{|c|}{$5-6$} & \multicolumn{2}{|c|}{$7-7$} & \multicolumn{2}{|c|}{$7-11$} & \multicolumn{2}{|c|}{$9-12$} \\
\hline & Raiz & Fôlha & Raiz & Fôlha & Raiz & Fôlha & Raiz & Fôlha & Raiz & Fôlha & Raiz & Fôlha & Raiz & Fôlha & Raiz & Fôlha \\
\hline $\begin{array}{l}1 \\
2 \\
3 \\
4\end{array}$ & $\begin{array}{l}62.500 \\
61.800 \\
60.600 \\
62 .(4 ; 1)\end{array}$ & $\begin{array}{l}25.500 \\
25.000 \\
25.000 \\
25.300\end{array}$ & $\begin{array}{l}51.300 \\
59.200 \\
50.200 \\
48.650\end{array}$ & $\begin{array}{l}29.200 \\
32.300 \\
30.600 \\
30.080\end{array}$ & $\begin{array}{l}77.400 \\
80.000 \\
78.200 \\
79.300\end{array}$ & $\begin{array}{l}49.000 \\
50.100 \\
49.200 \\
56.500\end{array}$ & $\begin{array}{l}34.300 \\
33.800 \\
34.000 \\
33.250\end{array}$ & $\begin{array}{l}34.700 \\
34.100 \\
34.100 \\
34.000\end{array}$ & $\begin{array}{l}34.300 . \\
36.300 \\
37.000 \\
35.800\end{array}$ & $\begin{array}{l}54.100 \\
54.300 \\
54.000 \\
53.480\end{array}$ & $\begin{array}{l}24.200 \\
22.600 \\
22.500 \\
22.500\end{array}$ & $\begin{array}{l}20.000 \\
20.300 \\
18.400 \\
20.100\end{array}$ & $\begin{array}{l}28.800 \\
25 . .800 \\
29.000 \\
29.000\end{array}$ & $\begin{array}{l}30.200 \\
30.200 \\
32.000 \\
31.300\end{array}$ & $\begin{array}{l}33.800 \\
34.400 \\
31.100 \\
31.100\end{array}$ & $\begin{array}{l}33.500 \\
33.000 \\
33.900 \\
34.500\end{array}$ \\
\hline Média & & & & & & & & & & & & & & & & \\
\hline
\end{tabular}

(1) 100 plantas por parcela.

\section{QUADRO I I}

Pêso de raizes e fôlhas de Nabo ẹm 1953 (2)

\begin{tabular}{|c|c|c|c|c|c|c|c|c|c|c|c|c|c|c|}
\hline \multirow{2}{*}{$\begin{array}{l}\text { Data } \\
\text { Repet. }\end{array}$} & \multicolumn{2}{|c|}{$29-3$} & \multicolumn{2}{|c|}{$29-4$} & \multicolumn{2}{|c|}{$29-5$} & \multicolumn{2}{|c|}{$27-6$} & \multicolumn{2}{|c|}{$26-7$} & \multicolumn{2}{|c|}{$31-8$} & \multicolumn{2}{|c|}{$29-9$} \\
\hline & Rai\% & Fôlha & Raiz & Fôlha & Raiz & Fôllid & Raiz & Fôlha & Rai\% & Fôlha & Raiz & Fôlha & Raiz. & Fôlha \\
\hline $\begin{array}{l}1 \\
2 \\
3 \\
4\end{array}$ & $\begin{array}{l}40.000 \\
39.400 \\
+1.400 \\
40.200\end{array}$ & $\begin{array}{l}36.000 \\
33.000 \\
37.000 \\
34.000\end{array}$ & $\begin{array}{l}40.600 \\
39.000 \\
40.000 \\
40.100\end{array}$ & $\begin{array}{l}37.800 \\
30.400 \\
30.000 \\
32.000\end{array}$ & $\begin{array}{l}28.000 \\
27.500 \\
28.100 \\
29.300\end{array}$ & $\begin{array}{l}22.000 \\
21.000 \\
22.000 \\
22.300\end{array}$ & $\begin{array}{l}17.100 \\
18.350 \\
17.850 \\
20.000\end{array}$ & $\begin{array}{l}25.950 \\
25.500 \\
25.900 \\
25.200\end{array}$ & $\begin{array}{l}13.000 \\
14.000 \\
12.100 \\
11.150\end{array}$ & $\begin{array}{l}31.000 \\
31.000 \\
30.700 \\
30.000\end{array}$ & $\begin{array}{l}20.000 \\
20.400 \\
20.000 \\
20.600\end{array}$ & $\begin{array}{l}15.000 \\
14.000 \\
13.400 \\
14.000\end{array}$ & $\begin{array}{l}20.000 \\
16.500 \\
16.400 \\
15.400\end{array}$ & $\begin{array}{l}13.700 \\
16.000 \\
15.200 \\
15.100\end{array}$ \\
\hline Médià & 40.250 & 35.000 & 39.925 & 32.550 & 28.225 & 21.825 & 18.32 .5 & $25.6 \div 40$ & 12.560 & 30.675 & 20.250 & 14.100 & 17.090 & 15.450 \\
\hline
\end{tabular}

(2) 100 plantas por parcela 


\section{QUADRO III}

Análise de variância de pêso das raizes em 1952

\begin{tabular}{l|r|r|r}
\hline $\begin{array}{c}\text { Causa da } \\
\text { variação }\end{array}$ & G.L. & S.Q. & \multicolumn{1}{|c}{ Q.M. } \\
\hline Repetição & 3 & 11.772 .500 & \\
Meses & 7 & 70.271 .508 .750 & 10.038 .786 .964 \\
Residuo & 21 & 82.313 .750 & 3.919 .702 \\
\hline
\end{tabular}

As médias de tratamentos tôdas com êrro padrão de $0,990 \mathrm{~kg}$, são dadas abaixo

\begin{tabular}{|c|c|}
\hline$\ldots \ldots \ldots$ & $78,725 \mathrm{~kg}$ \\
\hline Fevereiro & $61,725 \mathrm{~kg}$. \\
\hline Março .... & 52,337 \\
\hline Junho & 35,975 \\
\hline Maio & $33,837 \mathrm{k}$ \\
\hline Dezembro & $32,600 \mathrm{k}$ \\
\hline Novembro . . & $28,150 \mathrm{k}$ \\
\hline Julho & 22,95 \\
\hline
\end{tabular}

A diferença mínima significativa ao nivel de $5 \%$ de probabilidade, calculada pelo teste de TUKEY, foi de $4,712 \mathrm{~kg}$. Por êste Teste podemos dizer que a primeira média difere de tôdas as outras médias. A maior produção de raizes ocorreu em abril e a menor em julho. Verifica-se que a produção de junho e maio bem como a de dezembro e novembro não diferiram estatisticamente entre si. 


\section{QUADRO IV}

Análise de variância do pêso das fôlhas em 1952

\begin{tabular}{l|r|r|r}
\hline $\begin{array}{c}\text { Causa da } \\
\text { variação }\end{array}$ & G.L. & \multicolumn{1}{|c}{ S.Q. } & \multicolumn{1}{|c}{ Q.M. } \\
\hline Repetição & 3 & 106.429 .050 & \\
Meses & 7 & 3.783 .252 .350 & 540.464 .621 \\
Resíduo & 21 & 7.007 .550 & 333.693 \\
\hline
\end{tabular}

As médias de tratamentos tôdas com êrro de $0,288 \mathrm{~kg}$. são dadas abaixo:

\begin{tabular}{|c|c|c|}
\hline unho & & $53,970 \mathrm{~kg}$ \\
\hline Abril & & 49,700 \\
\hline Maio & & 34,225 \\
\hline Dezembro & $\ldots \ldots$ & 33,725 \\
\hline Novembro & $\ldots$ & 30,925 \\
\hline Março & & 30,525 \\
\hline Fevereiro & & 25,200 \\
\hline Julho . & & 19,700 \\
\hline
\end{tabular}

A diferença mínima significativa ao nível de $5 \%$ de probabilidade calculada pelo teste de TUKEY, foi de $1,371 \mathrm{~kg}$. Por esta podemos dizer que a primeira média difere de todas as outras médias. Verifica-se pelos dados da análise estatística que a maicr produção de fôlhas ocorreu em junho seguido de abril e maio e a menor produção de fôlhas ocorreu em julho.

$$
\text { QUADRO V }
$$

A análise de variância do pêso das raizes em 1953

\begin{tabular}{l|r|r|r}
\hline $\begin{array}{c}\text { Causa da } \\
\text { variação }\end{array}$ & G.L. & \multicolumn{1}{|c|}{ S.Q. } & \multicolumn{1}{c}{ Q.M. } \\
\hline Repetição & 3 & 1.043 .686 & \\
Meses & 6 & 2.997 .990 .893 & 499.665 .148 \\
Residuo & 18 & 26.916 .450 & 1.495 .358 \\
\hline
\end{tabular}


As médias de tratamentos tôdas com êrro padrão de $0,611 \mathrm{~kg}$., são dadas abaixo :

\begin{tabular}{|c|c|}
\hline Março & $40,250 \mathrm{~kg}$. \\
\hline Abril $\ldots \ldots \ldots \ldots \ldots$ & $39,925 \mathrm{~kg}$. \\
\hline Maio $\ldots \ldots \ldots \ldots \ldots$ & $28,225 \mathrm{~kg}$ \\
\hline Agôsto . & 20,250 \\
\hline Junho $\ldots .$. & $18,325 \mathrm{~kg}$. \\
\hline Setembro & $17,087 \mathrm{~kg}$. \\
\hline Julho & 12,5 \\
\hline
\end{tabular}

A diferença mínima significativa ao nivel de $5 \%$ de probabilidade calculada pelo teste de TUKEY, foi de $2,853 \mathrm{~kg}$. Verifica-se por êste Teste que as produções de março e abril não diferiram entre si, porém diferem dos demais meses; seguindo o mês de julho como o de menor produção.

$$
\text { QUADRO VI }
$$

Análise da variância do pêso das fôlhas em 1953

\begin{tabular}{l|r|r|r}
\hline $\begin{array}{c}\text { Causa da } \\
\text { variação }\end{array}$ & G.L. & S.Q. & Q.M. \\
\hline Repetição & 3 & 13.529 .553 & \\
Meses & 6 & 1.658 .386 .697 & 276.397 .782 \\
Resíduo & 18 & 62.636 .875 & 3.479 .826 \\
\hline
\end{tabular}

As médias de tratamentos todas com êrro padrão de $0,933 \mathrm{~kg}$. são dadas abaixo :

$$
\begin{aligned}
& \text { Março ......... } 35,000 \mathrm{~kg} \text {. } \\
& \text { Abril } \ldots \ldots \ldots \ldots \ldots \quad 32,550 \mathrm{~kg} \text {. } \\
& \text { Julho } \ldots \ldots \ldots \ldots \ldots \quad 30,675 \mathrm{~kg} \text {. } \\
& \text { Junho } \ldots, \cdots \cdots \cdots, \quad 24,888 \mathrm{~kg} \text {. } \\
& \text { Maio .......... } 18,250 \mathrm{~kg} \text {. } \\
& \text { Setembro } \ldots \ldots \ldots \ldots \quad 15,000 \mathrm{~kg} \text {. } \\
& \text { Agôsto .......... } 14,100 \mathrm{~kg} \text {. }
\end{aligned}
$$

A diferença minima significativa ao nível de probabilidade calculada pelo teste de TuKEY, foi de $4,357 \mathrm{~kg}$. Por êste Teste podemos dizer que a média de março não difere da de abril, porém, difere das demais. $O$ mês de agôsto foi o de menor produção, 
porém estatisticamente diferente do mês de junho e das demais médias acima dela.

Pelos resultados das análises estatística e das produções, veri. fica-se que o rendimento em raizes foi mais elevado em 1952 do que em 1953; e ainda nos dois anos em estudos, o mês de abril apresentou-se como um dos mais produtivos e julho com o menor rendimento.

Com relação a produção de fôlhas em 1952, verifica-se que em junho o maior pêso foi registrado, e julho o menor.

Em 1953 os Nabos exibiram, em março, o maior pêso em fôlhas, acompanhando assim o pêso das raizes, porém o menor rendimento coube a agôsto,qu ando o menor pêso de raizes tinha-se verificado no mesmo ano em julho.

Se relacionarmos os pêsos de fôlhas e raizes (Quadro I) verificaremos que em 1952, nos meses de maio, junho, novembro e dezembro o pêso das fôlhas suplantaram os das raizes. Em 1953, observa-se nos meses de junho e julho que as produções de fôlhas superaram as das raizes.

Estes resultados podem ser melhor apreciados no Gráfico I onde mostramos as produções de raizes e fôlhas durante o ano de 1952 e 1953. Verifica-se que em 1952 a produção de fôlhas se elevou de fevereiro a junho, decrescendo em julho para novamente se elevar atć dezembro.

Com relação ao pêso das raizes houve um decrescimo de fevereiro a julho e novamente um acréscimo até o fim do ano. Em 1953 o mesmo fenômeno se repetiu com relação ao pêso das raizes, porém com relação as fôlhas, houve certa variação. Enquanto em 1952 o pêso das fôlhas cresceu até junho em 1953 ele decresceu, para se elevar em junho e julho e novamente decresceu para agôsto e dai em diante deu mostra de ascender outra vez.

$\mathrm{O}$ Nabo prefere temperaturas mais amenas, entre 12 a $20^{\circ} \mathrm{C}$; temperaturas mais baixas causaram paralização no seu desenvolvimento e mais elevadas aliadas a maior iluminação precipitaram a sua maturação.

\section{CONCLUSÕES}

Pelos dados obtidos pode-se concluir :

$1^{\circ}$ ) O Nabo desenvolve-se bem durante quase todo o ano preferindo contudo o periodo de temperatura mais amena.

2..$^{\circ}$ As baixas temperaturas favoreceram a produção de fôlhas em detrimento das raizes. 
3..$^{\circ}$ As fôlhas representam de 30 a $50 \%$ do pêso das plantas.

\section{SUMMARY}

From an experiment carried out during 1952 and 1953 the author reached to the conclusion that turnip, Brassica rapus, L, developed well almost the year around, preferring however the period of milder temperatures. As the temperature dropped there was an increase in the total weitht of leaves against a decrease in the total weight of roots. The leaves counted for 30 to $50 \%$ of the total plant weight. 

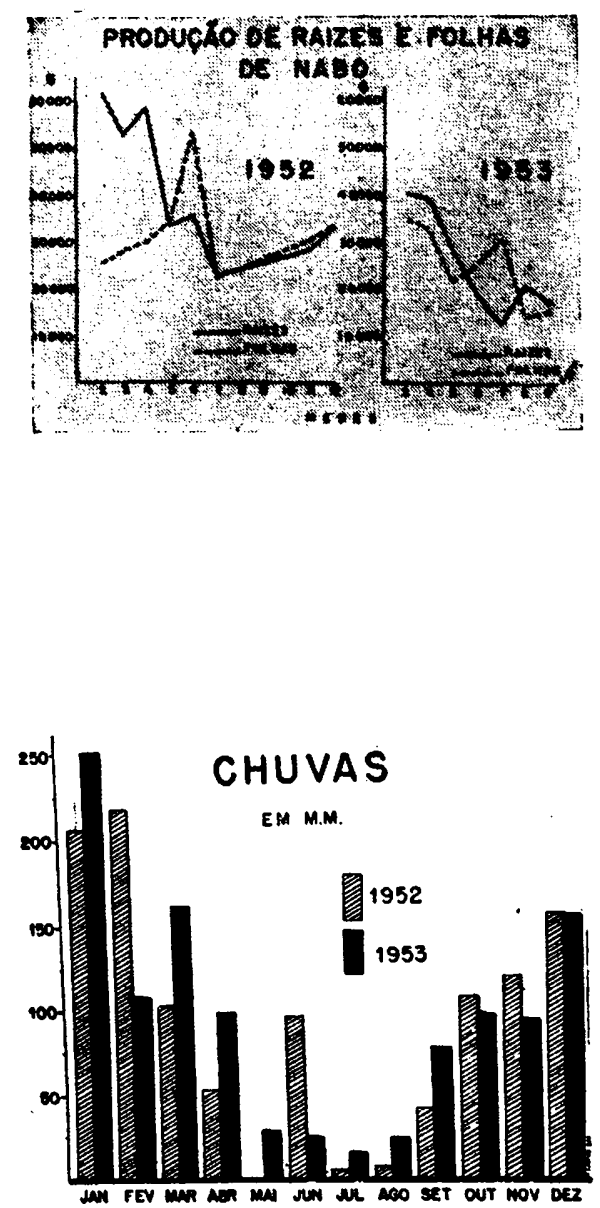